\title{
Efficacy and safety of methionine aminopeptidase 2 inhibition in type 2 diabetes: a randomised, placebo-controlled clinical trial
}

\author{
Joseph Proietto ${ }^{1}$. Jaret Malloy ${ }^{2}$ - Dongliang Zhuang ${ }^{2} \cdot$ Mark Arya $^{3} \cdot$ Neale D. Cohen ${ }^{4} \cdot$ Ferdinandus J. de Looze $^{5,6}$. \\ Christopher Gilfillan ${ }^{7}$. Paul Griffin ${ }^{8,9,10,11}$. Stephen Hall ${ }^{12,13}$. Thomas Nathow ${ }^{14}$. Geoffrey S. Oldfield ${ }^{15}$. \\ David N. O'Neal ${ }^{16}$ - Adam Roberts ${ }^{17} \cdot$ Bronwyn G. A. Stuckey ${ }^{18} \cdot$ Dennis Yue ${ }^{19} \cdot$ Kristin Taylor $^{2} \cdot$ Dennis Kim $^{2}$
}

Received: 14 March 2018 / Accepted: 24 May 2018 / Published online: 11 July 2018

(C) Springer-Verlag GmbH Germany, part of Springer Nature 2018

\begin{abstract}
Aims/hypothesis This multicentre randomised double-blind placebo-controlled clinical trial assessed the efficacy and safety of a methionine aminopeptidase 2 (MetAP2) inhibitor, beloranib, in individuals with obesity (BMI $\geq 30 \mathrm{~kg} / \mathrm{m}^{2}$ ) and type 2 diabetes $\left(\mathrm{HbA}_{1 \mathrm{c}} 53-97 \mathrm{mmol} / \mathrm{mol}[7-11 \%]\right.$ and fasting glucose $\left.<15.6 \mathrm{mmol} / \mathrm{l}\right)$.

Methods Participants were randomised (via a centralised interactive web response system) to placebo, 1.2 or $1.8 \mathrm{mg}$ beloranib s.c. twice weekly for 26 weeks. Participants, investigators and the sponsor were blinded to group assignment. The primary endpoint was the change in weight from baseline to week 26 . The trial was terminated early when beloranib development was stopped because of an imbalance of venous thromboembolism events in beloranib-treated individuals vs placebo that became evident during late-stage development of the drug.

Results In total, 153 participants were randomised, 51 to placebo, 52 to $1.2 \mathrm{mg}$ beloranib and 50 to $1.8 \mathrm{mg}$ beloranib. In participants who completed week 26 , the least squares mean \pm SE weight change (baseline $111 \mathrm{~kg}$ ) was $-3.1 \pm 1.2 \%$ with placebo $(n=22)$ vs $-13.5 \pm 1.1 \%$ and $-12.7 \pm 1.3 \%$ with 1.2 and $1.8 \mathrm{mg}$ beloranib, respectively $(n=25 ; n=19 ; p<0.0001)$. The change in $\mathrm{HbA}_{1 \mathrm{c}}$ (baseline $67 \mathrm{mmol} / \mathrm{mol}[8.3 \%]$ ) was $-6.6 \pm 2.2 \mathrm{mmol} / \mathrm{mol}(-0.6 \pm 0.2 \%)$ with placebo vs $-21.9 \pm 2.2 \mathrm{mmol} / \mathrm{mol}(-2.0$ $\pm 0.2 \%)$ or $-21.9 \pm 3.3 \mathrm{mmol} / \mathrm{mol}(-2.0 \pm 0.3 \%)$ with 1.2 or $1.8 \mathrm{mg}$ beloranib $(p<0.0001)$, respectively. The most common beloranib adverse events were sleep related. One beloranib-treated participant experienced a non-fatal pulmonary embolism.
\end{abstract}

Electronic supplementary material The online version of this article (https://doi.org/10.1007/s00125-018-4677-0) contains peer-reviewed but unedited supplementary material, which is available to authorised users.

Dennis Kim

dkim@zafgen.com

1 Department of Medicine (Austin Health), University of Melbourne, Heidelberg, VIC, Australia

2 Zafgen, Inc., 175 Portland St, 4th Floor, Boston, MA 02114, USA

3 Australian Clinical Research Network, Maroubra, NSW, Australia

4 Baker Heart and Diabetes Institute, Melbourne, VIC, Australia

5 AusTrials Pty Ltd, Sherwood, QLD, Australia

6 Discipline of General Practice, Faculty of Medicine, University of Queensland, Herston, QLD, Australia

7 Eastern Health Clinical School, Monash University, Box Hill, VIC, Australia

8 Q-Pharm Pty Ltd, Herston, QLD, Australia

9 QIMR Berghofer Medical Research Institute, Herston, QLD, Australia
10

11 Faculty of Medicine, University of Queensland, Herston, QLD, Australia

12 Emeritus Research, Malvern East, VIC, Australia

13 Institution for Rehabilitation Research, Monash University, Clayton, VIC, Australia

14 Ipswich Research Institute, Ipswich, QLD, Australia

15 Pendlebury Research, Cardiff, NSW, Australia

16 Department of Medicine, University of Melbourne, St Vincent's Hospital, Fitzroy, VIC, Australia

17 University Hospital Geelong, Geelong, VIC, Australia

18 Keogh Institute for Medical Research, University of Western Australia, Nedlands, WA, Australia

19 Royal Prince Alfred Hospital, Camperdown, NSW, Australia 


\section{Research in context}

\section{What is already known about this subject?}

- Previous trials in obese individuals indicate that the methionine aminopeptidase 2 (MetAP2) inhibitor beloranib, at doses up to $2.4 \mathrm{mg}$ for $\leq 26$ weeks, is generally well tolerated and results in placebo-corrected weight loss of up to $\sim 10 \%$

\section{What is the key question?}

- Is long-term treatment with beloranib safe and effective in obese individuals with type 2 diabetes?

\section{What are the new findings?}

- The clinical trial was stopped early because of an imbalance of venous thromboembolism events for beloranib vs placebo that became evident during late-stage development of the drug

- Beloranib resulted in a statistically significant clinically meaningful improvement in body weight that was supported by improvements in glycaemic measures and cardiometabolic variables

- The incidence of adverse events (AEs) was similar between beloranib and placebo; however, more participants treated with beloranib than placebo experienced AEs leading to trial discontinuation. The most common AEs with greater frequency in the beloranib groups vs placebo were sleep-related AEs, diarrhoea, injection-site reactions, lower respiratory tract infection and cough. Three reports of venous thromboembolism events occurred in beloranib-treated individuals

\section{How might this impact on clinical practice in the foreseeable future?}

- Although beloranib may create or otherwise exacerbate a hypercoagulable state, the significant efficacy findings support further investigation of other MetAP2 inhibitors designed to mitigate venous thromboembolism risk

Conclusions/interpretation MetAP2 inhibitors represent a novel mechanism for producing meaningful weight loss and improvement in $\mathrm{HbA}_{1 \mathrm{c}}$.

Trial registration: ClinicalTrials.gov NCT02324491

Funding: The study was funded by Zafgen, Inc.

Keywords Anti-obesity medication · Glucose-lowering medication · Glycaemic control · MetAP2

\section{Abbreviations}

AE Adverse event

hsCRP High-sensitivity C-reactive protein

MetAP2 Methionine aminopeptidase 2

PWS Prader-Willi syndrome

\section{Introduction}

Methionine aminopeptidase 2 (MetAP2) inhibitors are a novel drug class being investigated for the treatment of type 2 diabetes, obesity and metabolic disease. In preclinical models of obesity and diabetes, MetAP2 inhibitors produce weight loss characterised by markedly reduced adiposity and increased glycaemic control, as well as transiently reduced food intake $[1,2]$. The MetAP2 inhibitor beloranib has demonstrated consistent and substantial weight loss and glucose-lowering effects in clinical studies of general obesity, hypothalamicinjury-associated obesity and Prader-Willi syndrome (PWS)
[3-6]. This phase 2 clinical trial is the first to study the effects of MetAP2 inhibition with beloranib compared with placebo on glycaemic control and body weight in individuals with type 2 diabetes and obesity.

\section{Methods}

This multicentre randomised double-blind placebo-controlled phase 2 trial was conducted at 16 investigational sites in Australia from December 2014 to January 2016. The trial was terminated early because of an imbalance of venous thromboembolism events in beloranib-treated vs placebotreated individuals in beloranib clinical trials. The institutional review boards at all clinical sites approved the protocol before study initiation. All participants provided written informed consent. A sample size of 50 people per group was to provide $91 \%$ power to detect a mean difference of $5.0 \mathrm{~kg}$ assuming a standard deviation of $7.5 \mathrm{~kg}$. 
Eligible individuals aged $18-65$ years with $\mathrm{BMI} \geq 30 \mathrm{~kg} / \mathrm{m}^{2}$ had type 2 diabetes with $\mathrm{HbA}_{1 \mathrm{c}}$ 53-97 mmol/mol (7\%-11\%) and fasting plasma glucose $<15.6 \mathrm{mmol} / \mathrm{l}$ and were treated with diet/exercise or a stable dose of non-insulin glucose-lowering medication. Participants were randomised in a $1: 1: 1$ ratio via a centralised interactive web response system to placebo, $1.2 \mathrm{mg}$ beloranib or $1.8 \mathrm{mg}$ beloranib administered subcutaneously twice weekly (electronic supplementary material [ESM] Fig. 1). Randomisation was stratified based on sulfonylurea use (yes/no) and screening $\mathrm{HbA}_{1 \mathrm{c}}(<$ or $\geq 75 \mathrm{mmol} / \mathrm{mol}[<$ or $\geq 9 \%$ ]). Lifestyle (diet/exercise) counselling was provided to all participants.

The primary endpoint was the change in weight from baseline to week 26. Key secondary endpoints included the change from baseline to week 26 in glycaemic variables, the proportion of participants achieving weight loss targets and $\mathrm{HbA}_{1 \mathrm{c}}$ targets and the change in cardiometabolic variables. Safety evaluations throughout the study included assessment of incidence and severity of adverse events (AEs) as well as changes in laboratory measures, physical examination, vital signs and other safety measures.

The primary efficacy analysis was conducted on the per protocol population $(n=66)$, which included all randomised participants who received $\geq 75 \%$ of planned doses, had an endof-treatment efficacy assessment and did not have any notable protocol violations. Data were analysed using an ANCOVA model with change in weight as the dependent variable, treatment group, sulfonylurea use and baseline $\mathrm{HbA}_{1 \mathrm{c}}$ as factors and baseline weight as a covariate without imputation of missing data. Analyses performed on the per protocol population used observed data. Safety analyses were conducted on the safety population. The safety and intent-to-treat populations ( $n=152$ each) included all randomised participants who received $\geq 1$ dose of trial drug.

Data management and randomisation services were performed by BioClinica (Audubon, PA, USA) and statistical analyses were conducted by Agility Clinical (Carlsbad, CA, USA) and Pharmapace (San Diego, CA, USA). Data are available from the corresponding author on reasonable request.

\section{Results}

Participant disposition during the trial is shown in ESM Fig. 1. At the time of early study closure, 70 individuals had completed the study, 65 had not completed 26 weeks of treatment and 18 had discontinued the study (11 withdrew because of AEs, five withdrew consent, one was lost to follow up and one discontinued because of investigator decision).

Individuals in the intent-to-treat population were primarily white $(89 \%)$, non-Hispanic $(98 \%)$ and male $(57 \%)$, with mean \pm SD baseline age $54 \pm 7$ years, BMI $39.9 \pm 7.3 \mathrm{~kg} / \mathrm{m}^{2}, \mathrm{HbA}_{1 \mathrm{c}}$ $67 \pm 11 \mathrm{mmol} / \mathrm{mol}(8.3 \pm 1.0 \%)$ and duration of diabetes of
$7.1 \pm 4.9$ years. The majority $(93 \%)$ of participants were treated with $\geq 1$ glucose-lowering medication, most commonly biguanides $(72 \%)$ and sulfonylureas $(42 \%)$. There were no unexpected differences in demographics and baseline characteristics between the intent-to-treat and per protocol populations (ESM Table 1). Mean \pm SD exposures to placebo, $1.2 \mathrm{mg}$ and $1.8 \mathrm{mg}$ beloranib were $20.7 \pm 6.8$ (median 23.6 [min 1.6, $\max 27.4])$ weeks, $19.5 \pm 7.7(23.9[1.6,26.6])$ weeks and $18.5 \pm 8.3(22.1[0.4,26.7])$ weeks, respectively.

Weight loss with beloranib was observed as early as week 4 and progressed through to week 26 (Fig. 1a). At week 26, the least squares mean weight change $( \pm \mathrm{SE})$ in the placebo group was $-3.1 \pm 1.2 \%$ compared with $-13.5 \pm 1.1 \%$ in the $1.2 \mathrm{mg}$ beloranib group (placebo-corrected difference [95\% CI]: $-10.4 \%[-13.6,-7.2])$ and $-12.7 \pm 1.3 \%$ in the $1.8 \mathrm{mg}$ beloranib group $(-9.6 \%[-12.9,-6.4])$, both $p<0.0001)$ (ESM Table 2). Additionally, a substantially greater proportion of beloranib-treated participants achieved week 26 weight loss targets $\geq 5 \%, \geq 10 \%$ and $\geq 15 \%$ compared with placebo (Fig. 1b).

At week 26, the least squares mean change in $\mathrm{HbA}_{1 \mathrm{c}}( \pm \mathrm{SE})$ in the placebo group was $-6.6 \pm 2.2 \mathrm{mmol} / \mathrm{mol}(-0.6 \pm 0.2 \%)$ compared with $-21.9 \pm 2.2 \mathrm{mmol} / \mathrm{mol}(-2.0 \pm 0.2 \%)$ in the $1.2 \mathrm{mg}$ beloranib group (placebo-corrected difference [95\% $\mathrm{CI}]:-15.3 \mathrm{mmol} / \mathrm{mol}[-21.9,-9.8][-1.4 \%(-2.0,-0.9)])$ and $-21.9 \pm 3.3 \mathrm{mmol} / \mathrm{mol}(-2.0 \pm 0.3 \%)$ in the $1.8 \mathrm{mg}$ beloranib group $(-15.3 \mathrm{mmol} / \mathrm{mol}[-21.9,-8.7][-1.4 \%$ $(-2.0,-0.8)]$ ); both $p<0.0001$ (Fig. 1c, ESM Table 2). Additionally, a greater proportion of individuals in the beloranib treatment groups achieved $\mathrm{HbA}_{1 \mathrm{c}}$ levels $<53 \mathrm{mmol} / \mathrm{mol}(<7 \%)$ and $\leq 48 \mathrm{mmol} / \mathrm{mol}(\leq 6.5 \%)$ at week 26 compared with placebo (Fig. 1d). The week 26 least squares mean $\mathrm{HbA}_{1 \mathrm{c}}$ in both beloranib groups was $45 \mathrm{mmol} /$ mol $(6.3 \%)$ and the mean $\mathrm{HbA}_{1 \mathrm{c}}$ in the placebo group was $61 \mathrm{mmol} / \mathrm{mol}(7.7 \%)$ (Fig. 1e).

Fasting plasma glucose was significantly reduced vs placebo in both beloranib groups by week 8 and continued to decline through week 26 in beloranib-treated individuals (ESM Fig. 2a). Beloranib also produced improvements in other glycaemic variables compared with placebo (postprandial glucose, insulin sensitivity and beta cell function) and cardiometabolic markers (high-sensitivity C-reactive protein [hsCRP], adiponectin and leptin; ESM Fig. 2b, c and ESM Table 2).

More participants in the beloranib groups withdrew from the study because of an AE ( $n=5$ per beloranib dose group) than in the placebo group $(n=2)$. The most common reasons for withdrawal of beloranib were sleep related (e.g. insomnia, abnormal dreams, sleep disorder). There were no deaths. The most common AEs with greater frequency in the beloranib groups compared with placebo were sleep related (e.g. abnormal dreams, sleep disorder), diarrhoea, injection-site bruising, injection-site erythema, lower respiratory tract infection and cough (Table 1). Most AEs were mild to moderate in severity 

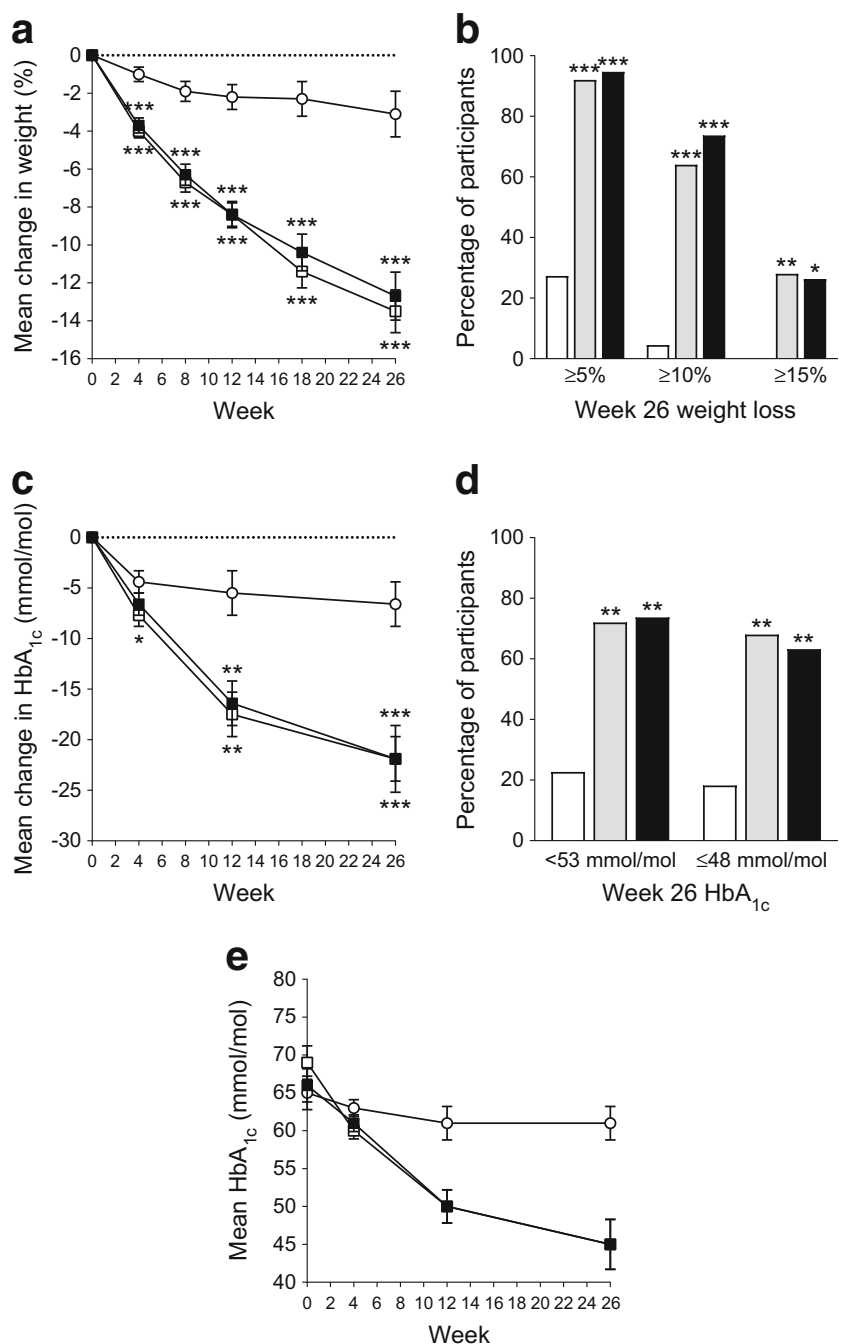

Fig. 1 (a) Least squares mean $\pm \mathrm{SE}$ for the change from baseline in weight. (b) Percentage of participants with weight loss of $\geq 5 \%, \geq 10 \%$ or $\geq 15 \%$ from baseline to week 26. (c) Least squares mean \pm SE for the change from baseline in $\mathrm{HbA}_{1 \mathrm{c}}$. (d) Percentage of participants who achieved an $\mathrm{HbA}_{1 \mathrm{c}}$ level of $<53 \mathrm{mmol} / \mathrm{mol}(<7 \%)$ or $\leq 48 \mathrm{mmol} / \mathrm{mol}$ $(\leq 6.5 \%)$ at week 26. (e) Least squares mean $\mathrm{HbA}_{1 \mathrm{c}}$ by visit. Data reflect observed data for the per protocol population $(n=66)$. For $(\mathbf{a}, \mathbf{c}, \mathbf{e})$, white circles, placebo $(n=22)$; white squares, $1.2 \mathrm{mg}$ beloranib $(n=25)$; black squares, $1.8 \mathrm{mg}$ beloranib $(n=19)$. For $(\mathbf{b}, \mathbf{d})$, white bars, placebo $(n=$ 22); grey bars, $1.2 \mathrm{mg}$ beloranib $(n=25)$; black bars, $1.8 \mathrm{mg}$ beloranib $(n=19)$. The differences between the $1.2 \mathrm{mg}$ and $1.8 \mathrm{mg}$ beloranib groups vs placebo for the body weight and $\mathrm{HbA}_{1 \mathrm{c}}$ efficacy endpoints were consistent and statistically significant $(p<0.05)$ regardless of the analysis population (per protocol or intent to treat) or imputation strategy (last observation carried forward [LOCF] or mixed-model repeated measures $[\mathrm{MMRM}]$ ) used to explore the sensitivity of the analysis (data not shown). $* p<0.05, * * p<0.01$ and $* * * p<0.0001$ for beloranib vs placebo

and self-limiting. The incidence of hypoglycaemia AEs was low and similar across treatment groups (4-6\%); all were mild and resolved. There were three AEs of thromboembolic nature (superficial thrombophlebitis, deep vein thrombosis, non-fatal pulmonary embolism); all occurred in beloranib-treated participants.
Table 1 AEs occurring from baseline to week 26

\begin{tabular}{|c|c|c|c|}
\hline $\mathrm{AE}$ & $\begin{array}{l}\text { Placebo } \\
n=51\end{array}$ & $\begin{array}{l}1.2 \mathrm{mg} \\
\text { beloranib } \\
n=52\end{array}$ & $\begin{array}{l}1.8 \mathrm{mg} \\
\text { beloranib } \\
n=49\end{array}$ \\
\hline Any serious $\mathrm{AE}$ & $2(4)$ & $4(8)$ & $1(2)$ \\
\hline $\begin{array}{l}\text { Exostosis (bone spur on } \\
\text { amputated leg stump) }\end{array}$ & 0 & 0 & $1(2)$ \\
\hline Musculoskeletal chest pain & 0 & $1(2)$ & 0 \\
\hline Atrial fibrillation & 0 & $1(2)$ & 0 \\
\hline $\begin{array}{l}\text { Psychotic disorder (stress induced } \\
\text { manic psychotic episode) }\end{array}$ & 0 & $1(2)$ & 0 \\
\hline Pulmonary embolism & 0 & $1(2)$ & 0 \\
\hline Abdominal pain (lower) & $1(2)$ & 0 & 0 \\
\hline Nephrolithiasis & $1(2)$ & 0 & 0 \\
\hline Any AE & $41(80)$ & $48(92)$ & $41(84)$ \\
\hline \multicolumn{4}{|c|}{ AEs occurring in $\geq 10 \%$ of participants in any treatment group } \\
\hline Diarrhoea & $7(14)$ & $10(19)$ & $9(18)$ \\
\hline Injection-site bruising & $6(12)$ & $10(19)$ & $7(14)$ \\
\hline Sleep disorder & $1(2)$ & $5(10)$ & $7(14)$ \\
\hline Injection-site erythema & $1(2)$ & $2(4)$ & $6(12)$ \\
\hline Upper respiratory tract infection & $10(20)$ & $14(27)$ & $6(12)$ \\
\hline Cough & $2(4)$ & $3(6)$ & $5(10)$ \\
\hline Abnormal dreams & $1(2)$ & $8(15)$ & $4(8)$ \\
\hline Nausea & $10(20)$ & $5(10)$ & $4(8)$ \\
\hline Lower respiratory tract infection & $2(4)$ & $7(14)$ & $3(6)$ \\
\hline Headache & $8(16)$ & $7(14)$ & $2(4)$ \\
\hline
\end{tabular}

Data are $n(\%)$ for the safety population $(N=152)$

\section{Discussion}

Here, we report that treatment with a MetAP2 inhibitor for 26 weeks produced placebo-corrected clinically meaningful weight loss $(-10 \%)$ and reductions in $\mathrm{HbA}_{1 \mathrm{c}}(-15.3 \mathrm{mmol} /$ mol $[-1.4 \%])$ in individuals with obesity and type 2 diabetes, and most participants achieved clinical $\mathrm{HbA}_{1 \mathrm{c}}$ and obesity treatment goals. Improvements in weight and $\mathrm{HbA}_{1 \mathrm{c}}$ were similar for both beloranib doses, despite a higher baseline weight in the lower $(1.2 \mathrm{mg})$ dose group, suggesting that the lower dose likely produced maximum efficacy.

The occurrence of unexpected serious venous thromboembolism AEs across beloranib clinical trials led to termination of beloranib development and investigation of the mechanism. Recently published data show that beloranib has effects on endothelial cells that influence pro- and anticoagulant factors [7]. Furthermore, prolonged ( $>24 \mathrm{~h}$ ) exposure, resulting from unique pharmacological properties of beloranib [7] as well as the suspension formulation, likely exacerbates these effects. Importantly, other MetAP2 inhibitors were recently shown to have similar beneficial effects on body weight and glycaemic control, but with a substantially improved safety profile compared with beloranib [7]. 
In addition to reductions in body weight and $\mathrm{HbA}_{1 \mathrm{c}}$, improvements in waist and hip circumference, fat mass, lipids, hsCRP, leptin and adiponectin (ESM Table 2) are consistent with previous observations of beloranib [3-6] and likely result from rapid weight loss as well as other weight-independent effects of MetAP2 inhibition. MetAP2 inhibitors are hypothesised to reduce body weight by increasing fat mobilisation and oxidation [2] and reducing food intake - beloranib produces a marked but transient reduction in food intake in preclinical studies [2] and improves measures of hunger and prospective food intake in obese individuals [3-5] and hyperphagia in PWS [6]. However, preclinical studies of obese pair-fed mice demonstrate that the decrease in food intake does not completely account for the reduction in body weight produced by MetAP2 inhibition [1]. Although weight loss of the magnitude documented in this study is sufficient to substantially improve glycaemic control [8], weightindependent effects of MetAP2 inhibition also likely play a key role. For example, MetAP2 inhibition attenuates activity of extracellular signal regulated kinase (ERK1/2) [9] and downstream factors such as retinoic acid-related orphan receptor $\alpha(\operatorname{ROR} \alpha)$ that influence the development of insulin resistance, inflammation and other metabolic disorders [10].

The current observations with MetAP2 inhibition demonstrate a potential new pathway to impact obesity and type 2 diabetes and support further investigations of this pathway in metabolic disease. Another MetAP2 inhibitor with an improved safety profile is in clinical development [7].

Acknowledgements We thank T. Haugen (Zafgen, Inc.) for assistance with clinical operations. Writing assistance was provided by S. K. Billes (August Scientific) and B. Clapper (BioMedCom) and was funded by Zafgen, Inc.

Data availability The datasets generated and/or analysed during the current study are available from the corresponding author on reasonable request.

Funding This work is sponsored by Zafgen, Inc. The sponsor was involved in study design and collection, analysis and interpretation of data, writing of the report, and decision to submit the report for publication.

Duality of interest JP, MA, FJdL, CG, PG, SH, TN, GSO, DNO, AR and DY received institutional grant support from Zafgen. NDC received institutional support from Zafgen and advisory board/speaking fees from Boehringer-Ingelheim, Lilly, Novo Nordisk, Astra Zeneca, Medtronic, Servier and Abbott. BGAS received institutional grant support from
Zafgen and speaking fees from Bayer and Besins. JM, DZ, KT and DK are employees of, and hold stock in, Zafgen.

Contribution statement JM, KT and DK took part in clinical trial design. JP, MA, NDC, FJdL, CG, PG, SH, TN, GSO, DNO, AR, BGAS, DY, JM and KT were responsible for screening and enrolment of participants and arranged informed consent. JP, MA, NDC, FJdL, CG, PG, SH, TN, GSO, $\mathrm{DNO}, \mathrm{AR}, \mathrm{BGAS}$ and DY were responsible for acquisition of data. JM, $\mathrm{DZ}, \mathrm{KT}$ and DK contributed to the statistical analysis. JM, DZ, KT and DK participated in data review and interpretation. JM, DZ and KT contributed to the writing of the manuscript. JM and DZ had full access to all data in the clinical trial and take responsibility for the integrity of the work. All authors critically reviewed and revised the manuscript and have read and approved the final version.

\section{References}

1. Rupnick MA, Panigrahy D, Zhang CY et al (2002) Adipose tissue mass can be regulated through the vasculature. Proc Natl Acad Sci U S A 99:10730-10735

2. Kim YM, An JJ, Jin YJ et al (2007) Assessment of the anti-obesity effects of the TNP-470 analog, CKD-732. J Mol Endocrinol 38: $455-465$

3. Kim DD, Krishnarajah J, Lillioja S et al (2015) Efficacy and safety of beloranib for weight loss in obese adults: a randomized controlled trial. Diabetes Obes Metab 17:566-572

4. Hughes TE, Kim DD, Marjason J, Proietto J, Whitehead JP, Vath JE (2013) Ascending dose-controlled trial of beloranib, a novel obesity treatment for safety, tolerability, and weight loss in obese women. Obesity (Silver Spring) 21:1782-1788

5. Shoemaker A, Proietto J, Abuzzahab MJ, Markovic T, Malloy J, Kim DD (2017) A randomized, placebo-controlled trial of beloranib for the treatment of hypothalamic injury-associated obesity. Diabetes Obes Metab 19:1165-1170

6. McCandless SE, Yanovski JA, Miller J et al (2017) Effects of MetAP2 inhibition on hyperphagia and body weight in PraderWilli syndrome: a randomized, double-blind, placebo-controlled trial. Diabetes Obes Metab 19:1751-1761

7. Burkey BF, Hoglen NC, Inskeep P, Wyman M, Hughes TE, Vath JE (2018) Preclinical efficacy and safety of the novel antidiabetic, antiobesity MetAP2 inhibitor ZGN-1061. J Pharmacol Exp Ther 365:301-313

8. Lean ME, Leslie WS, Barnes AC et al (2018) Primary care-led weight management for remission of type 2 diabetes (DiRECT): an open-label, cluster-randomised trial. Lancet 391:541-551

9. Datta B, Majumdar A, Datta R, Balusu R (2004) Treatment of cells with the angiogenic inhibitor fumagillin results in increased stability of eukaryotic initiation factor 2-associated glycoprotein, p67, and reduced phosphorylation of extracellular signal-regulated kinases. Biochemistry 43:14821-14831

10. Jetten AM, Kang HS, Takeda Y (2013) Retinoic acid-related orphan receptors alpha and gamma: key regulators of lipid/glucose metabolism, inflammation, and insulin sensitivity. Front Endocrinol 4:1 